\title{
Peertechz
}

\section{How artificial intelligence will effect jobs all around the world}

Received: 12 July, 2021

Accepted: 20 July, 2021

Published: 21 July, 2021

*Corresponding author: Mohd Kasib Siddiqui, Student in Shri Ramswaroop College of Engineering and Management, C-16, Sarvodaya Nagar, Lucknow, Uttar Pradesh, 226016, India, Tel: +918423326668; Email: kasibsiddiqui1234@gmail.com, kasib1234@outlook.com

Keywords: Artificial intelligence; Technology; Jobs; Automation; Robots; Software; Employment

https://www.peertechzpublications.com

Student in Shri Ramswaroop College of Engineering and Management, Lucknow, Uttar Pradesh, India

\section{Abstract}

The world is moving towards the era of Artificial Intelligence, most commonly known as automation, at a very great speed. Although, automation may be useful for humans but "How Artificial Intelligence will effect jobs all around the world?" is the real question here. People are already losing their employment because of automation and this is affecting their livelihoods. We have moved from using first generation computers to using and developing fifth generation computers in just 40 years. Previous generations were helpful as they eased our lives but they still had to be operated physically. Artificial Intelligence (Al) was released to remove this need of physical operation and it is already completing its requirement. People are willing to rely on robots and software more and more without realising that this may lead to decrease in employments all around the globe.

\section{Introduction}

In this modern and progressed world, AI or Artificial Intelligence is no more a fictional story which we used to hear as kids. It now exists in every corner of the world we live in. To give an idea of what AI basically is, it automates our tasks which results in improving our lives. The question here arises, as though AI helps in improving our lives, how it may affect the future workforce or the man labour? What effect will this alternative labour source have on the employment all around the world?

As rightly said by an American futurist and inventor, AI will reach human intelligence by around 2029. AI robots have a power of improving themselves based on experience and time far greater than humans. It will not be a surprise that an employee working as a data entry specialist gets replaced by an automated program which completes the same task within few seconds.

We have seen AI comforting humans, be it emotionally or physically. We have also seen AI helping humans in their own tasks. The biggest harm that is yet to be done by artificial intelligence is displacement of jobs in the short term. The amount of work we can automate with $\mathrm{AI}$ is vastly greater than before.

\section{Generations of computer and their drawbacks}

Computers were developed not for any entertainment purposes or email but to solve a serious problem of increasing crisis. The first computer to be ever built for economic and business related problems was UNIVAC in the year 1946. Until today, computers and software are being developed to solve all types of problems.

First generation: These computers were produced during the period 1946-1959. They were manufactured with vacuum tubes and were used in solving arithmetic and logical operations. They were operated using electronic values instead of key punching machines. Although these computers were helpful, they were too big in size and used too much of electricity. They also generated a lot of heat and had to be repaired frequently.

Second generation: These computers were produced during the period of 1959-1965. They used transistors instead of vacuum tubes to perform all kinds of operations. They required less space, were fast and reliable. They dissipated less heat and had storage capacity. Peripheral devices like printers were also supported. Despite of these advantages, they did not have any operating system and used assembly languages which were complex. They lacked intelligence in decision making and required high maintenance.

Third generation: The computers produced during the 
period of 1965- 1970 were termed as third generation. These computers used integrated circuits each of which consisted of thousands of transistors. These computers had very small size relatively and the transistors used in them were also very cheap. They were faster and supported secondary devices for storage. Concept of multiprogramming and time-sharing were incorporated in them but they lacked thinking and decision making capability. Also, they couldn't provide any information into their internal working.

Fourth generation: These computers were manufactured during the period 1970-1985 They used large IC's (integrated circuits) which were fit in their memory as microprocessors. These computers were very small in size and the cost of their operation was also very low. On line remote programming was also supported by which a person could execute his/ her programs by sitting at a distant place. These computers were less powerful and their speed of operation was also low as compared to mainframe computers. They had less storage capacity and needed improvement.

Fifth generation: These computers are emerging after 1985 with advanced and improved technology. These machines have "artificial intelligence" incorporated in them and use internally stored programs to make judgements and decisions like human beings. These computers, with the help of integrated circuits, can process non-numerical information like graphs and pictures. These are very fast computers and have the highest possible storage. They have the decision making capabilities which can aid humans in different sectors. Artificial Intelligence requires low level language to operate which may result in robots replacing humans. This can cause grievous unemployment problems. The human minds would become dull as all the creative thinking would be done by softwares and robots. AI has already hit many different sectors of management and has displaced many jobs until now.

\section{Al will replace humans}

With the advancement in the field of technology, humans are willing to depend on artificial intelligence more and more without realising that the same would affect them in their livelihood. People would do anything to make their tasks easier and more effective and what could be a better option if there are robots and softwares to do it. Artificial Intelligence will be replacing humans in various fields all around the world.

Recently Tesla company announced its auto-pilot feature which makes the work of the driver far more easier. Although people are not realising it, but when this feature is developed to its fullest, there would be no need of a driver. There would be taxis with no soul to drive it but software. We can only imagine how many taxi drivers would lose their livelihood with this automation. Same goes with airplane pilots. People travelling in an airplane with no one to pilot it but artificial intelligence.

Industries facing highest risks of automation are Transportation, Manufacturing and Storage.

Robots could displace more than 20 million jobs in manufacturing industries by 2030 from now onwards. People in these industries have already been replaced by AI robots. Separation of high quality seeds from those of poor quality is now being done by software and many other examples like this can be given in this context. The working sector which is most likely to be affected will be the people who have low educational qualifications.

\section{Major tasks and roles which are at risk}

Monotonous tasks can be very easily automated which results in making certain roles obsolete. For example, activities or tasks related to call centre operations, document verification/classification, content moderation, email writing and many others, are more related to technologies and less on human work.

The same can be applied on roles related to operation/ support of manufacturing factories. Robots are proving to be more dependable than humans. They can safely navigate the area, move parts from one place to any other, find and recognise different objects (such as products) or perform complex assembling operations.

AI proves to be very effective in handling even more complex activities for example those requiring handling and processing of many signals and giving results in real time operation. With this in consideration, employment of people even in technical fields is at risk. AI can collect desired data from different websites. It can create required models with raw data and give the result by providing furnished information. Thus, it is very difficult to say if automation will target only a few sectors of employment.

\section{An estimated study of job losses}

As already discussed, Artificial Intelligence is going to hit many working sectors drastically in consideration of jobs. Companies and governments from all around the world are conducting studies regularly as to how many job losses would occur due to automation and these studies are conducted yearly. Anxiety over job losses caused by automation has been around for a few years and is widely increasing.

\section{An estimated study shows:}

- One-third of the jobs in US are in danger due to automation.

- The number of jobs done by robots increases by $14 \%$ every year.

- Employees with low educational qualifications are at a greater risk.

- Artificial Intelligence is expected to add \$15 trillion to world economy by 2030 .

- Transportation, Manufacturing and Storage industries are facing the biggest chance to be automated.

- One-Third of the jobs will no longer exist in next 25 years. 


\section{Conclusion}

Automation may result in the loss of jobs all around the globe but it also gives the opportunity to move into a new world thereby creating a lot of new jobs and employment which humans currently cannot imagine. With the result of increasing technology and the speed with which it is being implemented in human lives prove that the era of robots is very close and the same is also required to make daily lives easier and more comfortable.
Discover a bigger Impact and Visibility of your article publication with

\section{Peertechz Publications}

\section{Highlights}

* Signatory publisher of ORCID

* Signatory Publisher of DORA (San Francisco Declaration on Research Assessment)

* Articles archived in worlds' renowned service providers such as Portico, CNKI, AGRIS, TDNet, Base (Bielefeld University Library), CrossRef, Scilit, J-Gate etc.

* Journals indexed in ICMJE, SHERPA/ROMEO, Google Scholar etc.

* OAl-PMH (Open Archives Initiative Protocol for Metadata Harvesting)

* Dedicated Editorial Board for every journal

* Accurate and rapid peer-review process

* Increased citations of published articles through promotions

* Reduced timeline for article publication

Submit your articles and experience a new surge in publication services (https://www.peertechz.com/submission).

Peertechz journals wishes everlasting success in your every endeavours.

Copyright: () 2021 Siddiqui MK. This is an open-access article distributed under the terms of the Creative Commons Attribution License, which permits unrestricted use, distribution, and reproduction in any medium, provided the original author and source are credited. 